\title{
Correction to: Basic Concepts, Organizing, and Displaying Data
}

\section{Correction to: \\ Chapter 1 in: M. A. Islam and A. Al-Shiha, Foundations of Biostatistics, https://doi.org/10.1007/978-981-10-8627-4_1}

The original version of the book was inadvertently published with incorrect information in Chapter 1 on Page 18; the correction is given below:

The explanation related to Table 1.5. stated as "Cumulative Percentage Frequency The percentage of women with weight less than $55 \mathrm{~kg}$ is $58.4 \%$ " has been corrected as "Cumulative Percentage Frequency The percentage of women with weight less than $50 \mathrm{~kg}$ is $58.4 \%$ or conversely the percentage of women with weight less than $55 \mathrm{~kg}$ is $91.7 \% "$ 